Filozofska fakulteta Univerze v Ljubljani

meta.lah@ff.uni-lj.si

\title{
AVTENTIČNA BESEDILA PRI POUKU FRANCOŠČINE KOT TUJEGA JEZIKA
}

\section{UVOD}

Namen pričujočega članka je analiza besedil v učbenikih, ki se uporabljajo pri pouku francoščine kot tujega jezika, pregled besedil, uporabljenih za testiranje na maturi iz francoščine in razmislek o rabi avtentičnih besedil pri pouku francoščine.

Kot navaja Morlat (2009), »vlada splošen konsenz o dejstvu, da imajo avtentični dokumenti nesporne prednosti in vedno pritegnejo učitelje in učence; $z$ njimi vnašamo $\mathrm{v}$ razred realno življenje in spoznavamo vsakdanjik ciljne kulture. Uporabimo lahko gradivo vseh vrst: ankete, vprašalnike, intervjuje, vremenske napovedi, radijske oddaje, male oglase, naznanila o porokah in smrtih, pesmi, reklame iz vseh vrst medijev. Prav zaradi uporabe avtentičnih gradiv so v učbenikih uporabljeni npr. administrativni formularji in besedila iz katalogov, ki učbenikom dodajo včasih tako zaželeni pridih po realnem življenju«.

Učbeniški komplet je za učitelja in za učenca/dijaka osnovno delovno gradivo. Glede na to, da je raba avtentičnih besedil in avtentičnih predlog nasploh eno od temeljnih načel komunikacijskega pristopa, pa tudi njegovih nadgradenj, današnjih metod (npr. na dejavnostih temelječega pristopa), je pričakovati, da bodo avtentična besedila $\mathrm{v}$ učbenikih prisotna vse od pojava komunikacijskega pristopa. Pričakovati bi bilo tudi, da bodo ta gradiva, glede na njihovo dostopnost, pogostejša v novejših učbenikih.

\section{KORPUS IN PREDPOSTAVKI}

Korpus za pregled avtentičnosti besedil predstavljajo štirje učbeniški kompleti: Le nouveau sans frontières, Panorama, Campus in Rond point. Gre za učbenike, ki so bili oz. so še vedno od konca osemdesetih let do danes najbolj uporabljani v slovenskem merilu.

$\mathrm{V}$ učbenikih in delovnih zvezkih smo analizirali besedila $\mathrm{v}$ dveh kategorijah: uvodna besedila in ostala besedila, namenjena razumevanju, obravnavanju civilizacije ali ustnemu in pisnemu izražanju. S pomočjo Adamove tipologije (Adam, 1997) smo besedila analizirali tudi glede na tipe. V pričujočem članku se bomo osredotočili na drugo kategorijo (t.i. »ostala« besedila), saj so uvodna besedila praviloma fabricirana in pisana posebej za učbenik. Tipe besedil bomo omenjali le $\mathrm{v}$ povezavi $\mathrm{z}$ avtentičnostjo. 
Izhodiščni predpostavki sta dve:

- avtentična besedila so prisotna $v$ vseh analiziranih učbeniških kompletih,

- glede na dostopnost besedil, bo avtentičnih besedil več v sodobnejših učbeniških kompletih kot v starejših.

\section{DEFINICIJA AVTENTIČNOSTI}

Kot ugotavlja J. Lewkowicz (1997: 166), razen dejstva, da ima izraz »avtentičnost« pozitiven naboj, ni konsenza, kaj ta izraz v resnici pomeni ali vključuje.

Večina avtorjev pod pojmom »avtentično gradivo« razume neobdelana ${ }^{1}$ besedila, katerih avtorji so rojeni govorci in so namenjena drugim rojenim govorcem v komunikacijske namene: gre torej za gradiva, ustvarjena $\mathrm{v}$ realnih življenjskih situacijah in ne za potrebe učenja jezika (Cuq, 2003: 29, Cuq, Gruca, 2002: 391, Grellet, 1981: 8). Gradivo je lahko pisno, slušno, avdio-vizualno, računalniško (Demari, 2004: 32).

Avtorji so si dokaj enotni glede definicije okoliščin nastanka avtentičnega besedila in se strinjajo, da gre pri tem za besedila, ki niso tvorjena za pedagoško rabo, njihova mnenja pa se razlikujejo glede uporabe besedil v razredu. Nekateri zagovarjajo uporabo takih besedil, kot se najdejo v virih: »Avtentičnost pomeni, da v ničemer ne spreminjamo izvornega besedila, ohraniti moramo tudi njegovo obliko. Časopisni članek moramo predstaviti tako, kot je bil predstavljen v časopisu: $\mathrm{z}$ enakimi črkami, enakimi naslovi in slikami, ki ga spremljajo. S standardizacijo besedil $v$ učbenikih ne samo zmanjšamo interes in motivacijo učenca, pač pa besedila tudi otežimo. Slike, velikost naslova, uporaba različnih vrst pisave (npr. poševna ali poudarjena) prispeva $\mathrm{k}$ temu, da učenec bolje zazna sporočilo besedila« (Grellet, 1981: 8). Drugi menijo, da si pri uporabi avtentičnih predlog v razredu lahko dovolimo določeno svobodo. M. Lemeunier-Quéré v svojih Priporočilih za uporabo avtentičnih gradiv $\mathrm{v}$ razredu navaja, da moramo razmisliti o tem, ali je »treba besedilo prilagoditi: ga skrajšati - kar moramo označiti z oznako [...], ga olajšati, tako da zamenjamo določene besede ali strukture« (2004: 29).

Opozoriti je treba tudi na dejstvo, da se avtentična besedila v razredu ne uporabljajo $v$ originalnem kontekstu. Zastavlja se torej vprašanje, ali je določeno besedilo sploh še avtentično, če ga uporabimo v okoliščinah, ki so povsem drugačne od izvorne situacije (reklama je na primer namenjena vzbujanju interesa potrošnikov in ne obravnavi v razredu) (Portine, 1983: 41; Boyer et al. 1990: 35, Cuq, Gruca, 2002: 393).

Med učitelji se veliko uporablja tudi izraz »semi-avtentična« besedila. Če izraz etimološko pomeni, da gre za besedila, ki so na pol avtentična, v praksi ni jasno, ali gre za avtentična prirejena besedila (kot predlaga Lemeunier-Quéré, gl. zgoraj) ali za umetna besedila, ki dobro posnemajo avtentična. V praksi se izraz semi-avtentična besedila uporablja $\mathrm{v}$ obeh pomenih.

fr. "brut" 


\section{KRATEK PREGLED RABE AVTENTIČNIH BESEDIL V UČBENIKIH IN PRI POUKU FRANCOŠČINE KOT TUJEGA JEZIKA: AVTENTIČNA BESEDILA SKOZI ZGODOVINO}

Pred letom 1970 se o uporabi avtentičnih besedil pri pouku ni dosti razmišljalo. Besedila, ki jih zasledimo $\mathrm{v}$ učbeniških kompletih, nastalih v tem obdobju, so pisana posebej za učbenike. Poglavitni cilj njihovih avtorjev ni bil ponuditi besedila za dejavnosti, povezane $z$ bralnim razumevanjem, pač pa ustvariti besedila, ki bodo služila kot iztočnice za druge, predvsem lingvistične cilje.

Primer iz učbenika Bonjour Line iz leta 1970, ki pripada avdio-vizualnim metodam poučevanja, je dovolj nazoren:

SPEAKER: C'est l'hiver. Il fait froid. Il y a de la neige. Les petites filles sont assises devant le feu. Alice lit. Josette regarde le feu.

ALICE: Écoute, j'entends du bruit.

JOSETTE: On frappe à la fenêtre.

ALICE: Viens voir!

JOSETTE: Qu'est-ce que c'est?

ALICE: C'est un oiseau. Il est noir. Il a un bec jaune.

JOSETTE: Il ouvre le bec. Il a faim.

ALICE: J'ai du pain dans ma poche.

JOSETTE: Ouvre la fenêtre.

ALICE: Oui, voilà.

(Boyer, Butzbach, Pendanx, 1990: 27-28)

Besedilo je pisano posebej za učbenik. Avtorji so ga napisali tako, da so sledili rangu najpogostejših besed, ki so se pojavljale v registru Le français fondamental. Besedišče, ki se v dialogu pojavlja, je besedišče, ki se uporablja v vsakdanji komunikaciji, vendar so avtorji popolnoma zanemarili značilnosti te komunikacje. $\mathrm{V}$ avtentični situaciji bi struktura stavkov povsem drugačna, predvsem pa bi deklici uporabljali medmete in vzklike, na primer »Oh! «, »Glej no«, »Daj no«, in podobno. Besedilo zato izpade papirnato in ima kaj malo skupnega $z$ resničnimi sporazumevalnimi situacijami, na katere naj bi učence pripravljalo.

Avtorji učbeniških kompletov so se zavedli naštetih pomanjkljivosti. Tako je učbenik C'est le printemps (izšel leta 1975), ki še vedno pripada avdio-vizualnim metodam poučevanja, zasnovan drugače; avtorji upoštevajo, da »po eni strani učenca vzpodbujajo k samostojnemu izražanju, po drugi strani pa mu za to ne nudijo ustreznih jezikovnih sredstev: pretekli časi so na primer obravnavani v glavnem šele ob koncu prvega učbenika, za ustrezno komunikacijo pa bi jih slušatelji morali poznati od samega začetka. (...) Jezik, ki ga bomo uporabljali, je skoraj avtentičen (v posnetkih upoštevamo ponavljanja, oklevanje, hitrost vsakdanjega govora. (...) Slušatelja bomo od samega začetka učenja seznanjali z različnimi jezikovnimi registri.« (C'est le printemps, priročnik za učitelje, citiran v Boyer et al. 1990: 29). 


\section{Za ilustracijo navajamo dva kratka odlomka iz tega učbenika:}

Situation: Devant une agence, une étudiante est en train de regarder un panneau de petites annonces.

Séquence 1

Yves: Qu'est-ce que tu fais là?

Evelyne: Ben, tu vois, je cherche une chambre.

Yves: Tiens, regarde cette annonce. Ça t'intéresse pas?

(...)

Séquence 3

Yves: C'est pas près de la fac?

Evelyne: $\mathrm{Si}, \mathrm{j}$ 'y vais tout de suite. Tu viens avec moi?

Yves: Si tu veux.

(Boyer et al., 1990: 29)

V primerjavi z odlomkom iz učbenika Bonjour Line lahko opazimo veliko razliko. Avtorji odlomka iz C'est le printemps uporabljajo jezikovni register, ki ustreza situaciji komunikacije, t.j. pogovoru med dvema mladima: uporabljajo medmete (»ben«, »tu vois«), pogovorne besede (»fac« namesto »faculté«), slovnične strukture, ki se uporabljajo $\mathrm{v}$ vsakdanjem govoru (npr. izpustitev prvega dela zanikanja: »C'est pas près de la fac« namesto »Ce n'est pas près de la fac «).

Kot opozarjajo avtorji priročnika za učitelje, gre pri tem učbeniku za skoraj avtentična ${ }^{2}$ besedila; čeprav so besedila pisana posebej za učbenik, so se njihovi avtorji skušali približati realnim življenjskim situacijam. Lahko bi rekli, da gre pri tem učbeniku za nekakšno prehodno, vmesno stopnjo med dvema doktrinama: tisto, ki je za uporabo v razredu priporočala povsem umetna besedila in tisto, ki gradi na uporabi izvirnih besedil.

Veliko vlogo pri uvajanju avtentičnih besedil v pedagoški proces sta v Franciji odigrali dve instituciji - BELC (Bureau pour l'enseignement de la littérature et de la civilisation françaises à l'étranger) in CREDIF (Centre de recherche et d'étude pour la diffusion du français). Obe instituciji, katerih cilj je bil (in je deloma še, čeprav $v$ mnogo manjši meri) predvsem širjenje poučevanja francoščine $\mathrm{v}$ tujini, sta aktivno sodelovali pri pripravi jezikovnih gradiv (sodelavci CREDIF-a so sodelovali tako pri projektu Le français fondamental kot pri projektu Un niveau seuil), didaktičnih gradiv za učitelje in učence (CREDIF npr. avdio-vizualna učbenika Voix et images de France in Bonjour Line, iz katerega je zgornji odlomek; pa enega prvih učbenikov, narejenih po komunikacijski metodi poučevanja, Archipel) in zagotavljali povezavo med raziskovalci in uporabniki gradiv, se pravi povezavo med teorijo in prakso (Cuq, Gruca, 2002:35-36). Pomembna je bila tudi njuna vloga v izobraževanju učiteljev, saj so praktično

$\overline{2}$ O tem, kakšna besedila so skoraj avtentična, bomo razmišljali v poglavju 5. 
vsi učitelji francoščine kot tujega jezika, ki so prihajali v Francijo, šli skozi enega od njihovih tečajev.

Ko so se okrog leta 1970 začele razprave o uporabi avtentičnih gradiv pri pouku, sta BELC in CREDIF zavzela nekoliko različni stališči. Znanstveniki CREDIF-a - med njimi zlasti D. Coste - so sicer priporočali uporabo avtentičnih gradiv, vendar so bili pri tem zelo previdni; pretirano uporabljanje izvirnih besedil naj bi po njihovem mnenju vodilo v »kult avtentičnih gradiv«; aktivnosti pri pouku pa bi se lahko sprevrgle $\mathrm{v}$ mehanično dešifriranje in razlago besedil. Sodelavci BELC-a pa so se dosti bolj radikalno zavzeli za uporabo avtentičnih gradiv, zlasti gradiva za slušno razumevanje (Debyser, 1979: 80-81).

Metodološke razprave so se kmalu začele odražati tudi v didaktični literaturi. Tako Vigner že leta 1980 pravi, da so potrebe poučevanja pripeljale do točke, na kateri je potrebno premisliti določene koncepte: koncept »besedila « je dvoumen in prepušča svoje mesto »diskurzu« ali še bolje "gradivu«, ki poleg lingvističnih vključuje tudi druge znake (grafične, tipografske, slikovne). Vigner še ne uporablja izraza »avtentično gradivo«, vendar lahko iz spiska besedil, ki jih priporoča za uporabo pri pouku (med drugim članki specializiranih revij, katalogi, imeniki, navodila za uporabo, slovarji, formularji, itn.) sklepamo, da gre za taka besedila (Vigner, 1980: 138-139).

Avtentična besedila se je pri pouku zares začelo uporabljati, ko so se prva taka besedila pojavila tudi $\mathrm{v}$ učbenikih. To se je zgodilo s pojavom komunikacijskih metod poučevanja, se pravi po letu $1980 .{ }^{3}$ Germain (2001: 207) v svojem pregledu učbenikov pravi: »Ena od značilnosti komunikativnega pristopa je, da učitelj $\mathrm{v}$ največji možni meri posega po t. i. avtentičnih gradivih, se pravi tistih, ki niso narejeni posebej za uporabo v razredu«; Galisson pa komunikacijskim metodam poučevanja pripisuje izključno uporabo avtentičnih gradiv. ${ }^{4}$

Kot kaže anketa, ki jo je v začetku 1. 2004 med učitelji po svetu preko medmrežja opravil Demari (2004: 32-33), se danes avtentična besedila v razredu veliko uporabljajo, vendar ne za vsako ceno. Učitelji po njih posegajo veliko bolj kritično kot pred nekaj desetletji.

Podoben je tudi trend na angleškem govornem področju. Če je 1. 1981 F. Grellet opozarjala na to, da je "potrebno uporabljati avtentična besedila, kjer je le mogoče« (1981: 7), se Urquhart in Weir od takih priporočil oddaljita: »Dolga leta je obstajal konsenz, naj bi bila besedila, ki jih uporabljamo za poučevanje in testiranje, avtentična, čeprav je njihova uporaba postala bolj stvar zdrave pameti kot pa - kot na začetku - skoraj misijonarska dogma. Obstajajo mnenja, da pri testiranju heterogene populacije uporaba povsem avtentičnih besedil ni nujna« (1998: 141).

\footnotetext{
Prvi učbenik, narejen po komunikacijski metodi poučevanja, je Cartes sur table, izšel 1. 1981; leto kasneje mu je sledil Archipel.

4 Izročki s predavanj v okviru podiplomskega študija, Pariz - Université Paris III - Sorbonne Nouvelle, $1996 / 97$
} 


\section{RABA AVTENTIČNIH GRADIV}

\subsection{Raba avtentičnih gradiv v razredu}

Uporaba avtentičnih gradiv $\mathrm{v}$ razredu ima $\mathrm{z}$ didaktičnega vidika veliko prednosti. Čeprav take vrste gradiva $v$ razredu navadno uporabljamo v drugačnem kontekstu od tistega, za katerega so bili zamišljeni, učence $\mathrm{z}$ njihovo pomočjo postavimo $\mathrm{v}$ realno situacijo in jim omogočimo neposreden stik z jezikom, ki se ga učijo. Tako je na primer posnetek napovedovalca $z$ letališča ali železniške postaje v razredu res uporabljen izven konteksta, vendar lahko situacija kaj kmalu postane realna: učenec bo že ob prvem pravem stiku z deželo, katere jezik se uči, izpostavljen identičnemu besedilu. De Ferrari (2006, spletni vir) navaja vrsto prednosti uporabe avtentičnih dokumentov, ki se odražajo na kognitivni, sociokulturni, psihoafektivni in komunikacijski ravni.

S pomočjo avtentičnih gradiv lahko uspešno združimo učenje jezika in civilizacije; pri vremenski napovedi lahko na primer obdelamo jezikovne strukture, pa tudi pokrajine posamezne dežele.

Kot poudarjajo Cuq in Grucajeva ter Kawecki, so avtentična gradiva tudi vir motivacije: učenec se z njihovo pomočjo zave svojega napredka, poleg tega pa razvije sposobnosti sklepanja. Veliko možnosti je namreč, da pri avtentičnem besedilu ne bo razumel vsake podrobnosti, vendar je »dober « učenec tujega jezika tisti učenec, ki bo izhajal iz tistega, kar že ve in sklepal o neznanem (Cuq, Gruca, 2002: 392; Kawecki, 2004: 31).

Seveda avtentična besedila pri pouku tujega jezika še posebej na začetni stopnji učenja ne morejo nadomestiti osnovnega učbenika. Učitelj jih mora izbirati skrbno in upoštevati starost in interese učencev. Zavedati se mora, da so določena avtentična besedila po tematiki za učence lahko nezanimiva. Poseben problem predstavlja aktualnost avtentičnih besedil: če bo učitelj izbral zelo aktualna besedila - ki bodo za njegove učence seveda najbolj zanimiva - se mu lahko zgodi, da jih bo uporabil samo enkrat, saj za naslednjo generacijo učencev ne bodo več prišla v poštev. Pred uporabo izvirnih gradiv je potreben tudi razmislek o njihovi dolžini in težavnosti (Cuq, Gruca, 2002: 393).

Učitelji navajajo, da v razredu uporabljajo različne vrste avtentičnih gradiv: odlomke iz brošur, katalogov, kuharske recepte, časopisne članke, reklame, poljudno-znanstvene članke, elektronsko pošto, šansone, radijske posnetke, video posnetke, itn. Ena od učiteljic opozarja na dejstvo, da se zaradi večje uporabe avtentičnih besedil $v$ razredu uporablja manj književnih besedil, kar je velika škoda ${ }^{5}$ (Demari, 2004: 33).

\subsection{Raba avtentičnih gradiv pri testiranju}

Za uporabo avtentičnih gradiv $\mathrm{v}$ testne namene lahko navedemo vsaj dva razloga. Prvi je priprava učenca na realne življenjske situacije, kar je nedvomno osnovni cilj jezikovnega pouka.

\footnotetext{
Naša opomba: tudi književna besedila so avtentična besedila.
} 
Drugi razlog pa je povratni učinek ${ }^{6}$ testiranja na pouk. Če želimo, da učitelji pri pouku uporabljajo več avtentičnih gradiv, jih moramo vključiti v preverjanje. Prišlo bo do pozitivnega povratnega učinka na pouk, saj bodo učitelji v razredu bolj vadili s pomočjo takšnih gradiv, kot jih lahko pričakujejo pri preverjanju (Hughes, 1989: 44-47). Na daljši rok se bo izbira gradiv za preverjanja odrazila tudi v učbenikih: tako je pričakovati, da bo v novejših učbenikih francoščine več avtentičnih besedil kot v starejših.

Kljub argumentom, ki govorijo $\mathrm{v}$ prid uporabi avtentičnih besedil pri testiranju, je treba upoštevati tudi dejstvo, da je učenec oz. dijak pri preverjanju v posebnem položaju. Zaveda se namreč, da je z rezultati testiranja pogojena najmanj njegova ocena med šolskim letom, lahko pa tudi ocena na določenem izpitu, ki vpliva na pomembnejše odločitve, ${ }^{7}$ zato je pod velikim pritiskom. Lahko se zgodi, da pri nalogi, ki bi jo v normalnih okoliščinah - se pravi, v razredu, morda $z$ malenkostno pomočjo učitelja ali slovarja - rešil brez posebnih težav, popolnoma odpove. $\mathrm{V}$ takem primeru uporaba popolnoma avtentičnih besedil ni smiselna (Urquhart in Weir, 1998:141). S prirejanjem besedil po določenih kriterijih lahko ohranimo videz avtentičnosti, vseeno pa besedila prilagodimo znanju in sposobnosti učencev oz. dijakov.

Pomen avtentičnosti besedil pri testiranju je, zlasti pri slušnem razumevanju, preučevala J. Lewkowicz (1997). Izvedla je dva poskusa. Pri prvem je skušala ugotoviti, ali testirani pri testiranju prepoznajo avtentična besedila, pri drugem pa določiti vpliv tipa naloge na rezultat izpita. Zanima nas zlasti prvi poskus, ki ga je izvedla tako, da je rojenim govorcem in tujim učiteljem angleščine predvajala 12 odlomkov, izmed katerih so morali izbrati avtentična besedila. Kljub temu, da so testirani za prepoznavanje skušali uporabljati določene kriterije (navajajo intonacijo, izgovor, ponavljanja, uporabo popolnih stavčnih struktur - verjetno pri prirejenih besedilih, poseganje po besedi, zlasti pa hitrost govora, 1997: 169) in se niso odločali zgolj intuitivno, se je izkazalo, da niti rojeni govorci niti tujci v glavnem ne ločijo med avtentičnimi in t.i. »pedagoškimi« besedili, se pravi besedili, narejenimi posebej za testiranje. ${ }^{8}$ Testirani so se pri izpitu dosti bolj kot z vprašanjem avtentičnosti besedila ukvarjali z drugimi stvarmi, na primer s poznavanjem tehnike reševanja nalog. J. Lewkowicz zaključuje, da se avtentičnosti besedil pri preverjanju pripisuje prevelik pomen in je le-ta dosti pomembnejša za tvorce nalog kot pa za tiste, ki so jim naloge namenjene. Po njenem mnenju je pri preverjanju treba bolj upoštevati druge stvari, na primer praktičnost samega testa.

\subsection{Avtentična besedila pri pouku in testiranju francoščine pri nas}

V anketi, poslani po elektronski pošti učiteljem francoščine, na katero se je odzvalo 15 učiteljev $^{9}$, smo dobili naslednje odgovore:

\footnotetext{
6 an. backwash

Pri tem mislimo na izpite kot so eksterna preverjanja ob koncu devetletke in na maturo; v obeh primerih uspeh na izpitu pogojuje učenčevo/dijakovo nadaljnje šolanje.

8 Opozoriti na dejstvo, da so tudi prirejena besedila posneta zelo profesionalno: gre za govorce, ki o določeni temi govorijo prosto in ne berejo, kot se to dogaja pri t.i. "lekcijah" v učbenikih.

9 Vzorec je zelo majhen, vendar tipičen glede na število učiteljev francoščine v Sloveniji (na gimnazijski ravni okoli 40 učiteljev). Odgovore navajamo le kot ilustracijo.
} 
- vseh petnajst učiteljev navaja, da pri pouku uporabljajo avtentična neumetnostna besedila. Navajajo različne vire, dva med njimi samo revije Mary Glasgow Magazines, v katerih najdemo večinoma že prirejena besedila, zato se za ta dva učitelja sprašujemo, ali res uporabljata avtentična besedila. Ostali viri, ki jih navajajo, so: članki iz revij in časopisov (Femme Actuelle, Phosphore, Okapi, Paris Match, Les Clés de l'actualité, Marie Claire, l'Express), besedila z medmrežja;

- kriteriji, po katerih izbirajo besedila, so: razpoložljivost na trgu, primerna tematika (kot primerne navajajo zlasti tiste teme, ki se pokrivajo s temami v katalogu za maturo), interes dijakov, uporabnost besedišča, aktualnost, teme, ki manjkajo v učbeniku;

- 8 učiteljev besedil ne prireja (med temi dva učitelja, ki uporabljata besedila Mary Glasgow Magazines);

- 7 učiteljev besedila občasno prireja: jih krajšajo, pretežke besede ali strukture nadomeščajo z lažjimi, razlagajo neznane pojme, povezane s civilizacijo, prevajajo neznane besede, posamezne odlomke povzemajo;

- 13 učiteljev pri pouku uporablja tudi književna besedila (eden s pripisom »redko«);

- 8 učiteljev pri pouku uporablja manj književnih besedil zaradi večje uporabe avtentičnih besedil;

- 5 učiteljev ne vključuje besedil v teste in ostala preverjanja znanja; v glavnem navajajo, da se jim zdijo ostale vaje $e^{10}$ primernejše, ena učiteljica še dodaja: »Ker me spremlja (morda neosnovana) bojazen, da to vzame preveč časa in premalo pokaže«;

- 5 učiteljev vključuje v teste in ostala preverjanja znanja avtentična in prirejena besedila, $4 \mathrm{v}$ preverjanja vključujejo samo avtentična besedila, eden pa samo prirejena.

Če sodimo po rezultatih ankete, učitelji v razredu v glavnem uporabljajo avtentična besedila, ki jih večinoma tudi vključujejo v teste in/ali ostala preverjanja znanja. Pri slovenski maturi iz francoščine pa se uporabljajo avtentična in prirejena besedila. Prirejena besedila, uporabljena pri maturi, bi lahko imeli za skoraj avtentična (Urquhart in Weir, 1998: 141).

Poglejmo še, kakšno je stanje pri splošni maturi iz francoščine. Za preverjanje slušnega razumevanja se uporabljajo zgolj avtentična besedila.

Drugačna je slika pri preverjanju bralnega razumevanja; od začetka t. i. »nove« mature so bila za preverjanje bralnega razumevanja uporabljena tri avtentična časopisna besedila. Razlogi za prirejanje besedil so dveh vrst:

- besedila so predolga in se za pripravo nalog krajšajo,

- besedila so mestoma pretežka za razumevanje, pri prirejanju se s sinonimi zamenjajo besede, ki se sestavljalcem nalog zdijo prezahtevne, prav tako se izpustijo ali prilagodijo s civilizacijo povezani pojmi, ki bi lahko ovirali razumevanje.

10 Iz odgovorov je razbrati, da bralnega razumevanja ne preverjajo, primernejše se jim zdijo npr. slovnične vaje. 


\section{ANALIZA BESEDIL V UČBENIKIH}

\subsection{Korpus in definicije avtentičnosti}

Pri analizi korpusa bomo uporabljali izraze avtentična, avtentična prirejena in neavtentična besedila.

Pod izrazom avtentična besedila razumemo besedila, ki izvorno niso bila tvorjena $\mathrm{v}$ pedagoške namene in niso spremenjena, po možnosti je ohranjena tudi njihova originalna postavitev.

Pod izrazom avtentična prirejena besedila razumemo besedila, ki so prirejena po avtentičnih besedilih: spremenjena je njihova postavitev, so krajšana, posamezne besede ali izrazi so zamenjane, vsebujejo razlage posameznih besed ali izrazov.

Neavtentična besedila so besedila, tvorjena posebej za rabo v razredu. Imenujemo jih tudi pedagoška besedila.

Pri analizi korpusa bomo uvedli še pojem navidezno avtentična besedila. Pri teh besedilih gre za besedila, ki so po vsej verjetnosti avtentična, vendar avtorji učbenikov niso navedli njihovega vira: npr. plakati, vozni redi, itn.

$\mathrm{Za}$ učitelja tujega jezika je najti dober učbenik prioriteta in izziv. Kot ugotavlja Vigner (1997: 72), je odnos učiteljev do učbenikov ambivalenten: neprestano so na lovu za »dobrim « učbenikom, ki bi po njihovem mnenju znanja in aktivnosti predstavljal na ustrezen način, hkrati pa tudi ves čas izražajo svoje nezadovoljstvo nad učbeniki, ki jih uporabljajo in se masovno zatekajo k fotokopiranju.

Položaj slovenskega učitelja francoščine ni nič drugačen. Razdvojenost in težke odločitve še povečuje dejstvo, da so avtorji učbenikov francoščine kot tujega jezika v Franciji očitno odkrili pomembno tržno nišo: večina založb letno izdaja nove učbenike, ki jih učitelji francoščine po svetu pridno kupujejo. Cuq in Gruca (2002: 272-273) v svojem pregledu učbenikov med leti 1999 do 2001 za isto ciljno publiko (adolescents/adultes) navajata 11 učbeniških kompletov; ${ }^{11}$ vsi temeljijo na komunikacijski metodi poučevanja, razlikujejo se le po tem, da nekateri vsebujejo tudi medmrežno različico, drugi pa CD-rom.

\subsection{Pedagoška in ostala besedila}

Poleg različnih nalog so ena osnovnih sestavin učbenikov besedila. Ta so nedvomno tista komponenta učbenika, ki ga najbolj določa. Pred avtorji učbenikov je težavna naloga tvorjenja in izbire besedil. V večini učbenikov tujih jezikov in tudi v učbeniških kompletih, ki sestavljajo naš korpus, se besedila delijo na "pedagoška " besedila, ki so bila napisana posebej za učbenik, in na besedila, ki po svoji primarni funkciji niso bila namenjena uporabi $v$ razredu in so bolj ali manj avtentična.

Med »pedagoška « besedila štejemo vsa besedila, namenjena bralnemu in slušnemu razumevanju, predloge za ustno in pisno izražanje, besedila, povezana s predstavitvijo civilizacije in različne razlage, pa tudi vaje: slovnične, fonetične vaje,

11 Champion, Reflets, Parle-moi français, Accord, Forum, Initial, Cours de la Sorbonne - Langue et civilisation françaises, Communication express, Funambule, Studio 60, Studio 100. 
vaje za besedišče in podobno. Besedila so napisali avtorji, ki se imajo za »imetnike znanj« in svojo vlogo vidijo $v$ tem, da znanje posredujejo določenim naslovnikom, ki znanja nimajo oz. je njihovo znanje različno (od učencev v osnovni šoli do študentov) (Beacco in Darot, 1984: 56-57).

V zadnjih desetletjih je bilo v Franciji napisanih nekaj člankov na temo učbenikov. Vigner (1997: 72-77) je primerjal učbenike za več predmetov iz različnih obdobij. Ugotovil je, da je "pedagoški jezik «12 danes zelo originalen in od učenca-bralca zahteva napor, ki ga nikakor ne moremo primerjati s tistim izpred stoletja, in veliko večjo aktivnostjo učenca. Barjolle, ki ga navaja Vigner, je pregledal šest novejših učbenikov, ki so namenjeni pouku francoščine kot materinščine. Ugotavlja, da se v teh učbenikih $\mathrm{v}$ dokaj izenačeni meri prepletajo podajanje slovnice, pravopisnih pravil, besedišča in aktivnosti za ustno in pisno izražanje. Opozarja na dejstvo, da nekateri avtorji pozabljajo na branje. Nekateri učbeniki sicer vsebujejo besedila, namenjena bralnemu razumevanju, vendar so vaje, ki so tej aktivnosti namenjene, povsem enake kot tiste, namenjene slovnici. Gre za preprosto prepoznavanje ali iskanje posameznih besed. Avtorji od bralca nikoli ne zahtevajo, da besedilo prebere, prepozna njegovo dinamiko in skuša določenemu tipu izrekanja pripisati specifično vrednost.

\subsection{Besedila in uporabniki učbenikov}

Seveda učenci/dijaki, ki so jim besedila namenjena, niso nepopisani listi papirja oz. "prazne posode« (Apple, Christian-Smith, 1998; citirano po Justin, 2003: 5). $\mathrm{Na}$ njihovo sprejemanje vsebine učbenikov vplivajo njihove biografije, prepričanja in predhodno pridobljena vednost. Učenci sporočila sprejemajo na različne načine, Justin po že omenjenih avtorjih povzema tri: podrejeno branje (nekritično sprejemanje sporočil), pogajalski odgovor (kritičen odnos do nekaterih podrobnosti v sporočilih, sprejemanje splošne usmeritve in tolmačenja stvarnosti, kot ga predstavlja učbenik), nasprotovalni odgovor (zavračanje tistega, kar posreduje učbenik) (Justin, prav tam).

$V$ našem primeru bi bilo zelo zanimivo vedeti, kakšen je odnos učencev/dijakov do besedil $\mathrm{v}$ učbenikih in ali se ta odnos spreminja glede na namen besedila. Po pogovorih s študenti, ki vpisujejo predmet Metodika pouka francoskega jezika, lahko sklepamo, da imajo nekateri izrazito odklonilna stališča do besedil, ki predstavljajo t.i. uvodna besedila: ta besedila se jim zdijo umetna in popolnoma neživljenjska. Veliko bolj pozitivna stališča izražajo v zvezi z avtentičnimi besedili, vključenimi v učbenike. Će imajo tudi učenci/dijaki podoben odnos do besedil, potem pri njih ne gre več za podrejeno branje. Vprašanje odnosa do besedil oz. načina sprejemanja besedila bi si zaslužilo temeljitejšo obravnavo, ki žal presega okvire tega članka.

\subsection{Analizirani učbeniki}

Za analizo smo izbrali štiri učbeniške komplete, ki so vsi namenjeni isti ciljni publiki; adolescentom in odraslim:

12 fr. écritures pédagogiques 
- Le Nouveau sans frontières, prvič izšel 1. 1988, avtorji Michèle Verdelhan, Michel Verdelhan, Philippe Dominique, Jacky Girardet - v nadaljevanju NSF,

- Panorama, prvič izšel 1996, avtorja Jacky Girardet, Jean-Marie Cridlig, v nadaljevanju $P$,

- Campus, prvič izšel 2002, avtorja Jacky Girardet, Jacques Pécheur, v nadaljevanju C.

- Rond point, prvič izšel 2004, avtorji Josiane Labascoule, Christian Lause, Corinne Royer, v nadaljevanju RP.

Razlogov za izbiro učbeniških kompletov je več. Najpomembnejši je gotovo ta, da so prav ti štirje učbeniški kompleti najbolj uporabljani v slovenskem prostoru. Dolga leta sta bila najbolj uporabljana Le nouveau sans frontières in Panorama, za njima nekoliko manj Campus, ki je nadgradnja Panorame. V zadnjih letih učitelji največ uporabljajo Rond point.

Pri prvih treh učbeniških kompletih je sodelovala ista avtorica, Jacky Girardet.

\subsubsection{Analizirana besedila}

$\mathrm{Za}$ analizo smo izbrali naslednja besedila:

- vsa uvodna besedila, se pravi besedila, ki uvajajo nove enote učbenika in tvorijo zgodbo skozi več poglavij. V sodobnih učbenikih francoščine so ta besedila praviloma dialoška besedila, ki so natisnjena v knjigi in posneta na kaseto ali zgoščenko ${ }^{13}$ in so torej namenjena bralnemu ali slušnemu razumevanju. Za analizo smo jih izbrali, ker za učitelja in dijaka predstavljajo osnovno delovno gradivo. Zaradi posnetkov, ki le malo posnemajo realne življenjske situacije, jih nekateri učitelji uporabljajo zgolj kot pisna besedila;

- ostala besedila v učbeniku, ki so namenjena bralnemu razumevanju in obravnavanju civilizacije, razen književnih besedil; ${ }^{14}$

- besedila v delovnem zvezku, za katera je iz navodila ali oznake razvidno, da so namenjena bralnemu razumevanju in/ali služijo kot iztočnica za ustno ali pisno izražanje.

Pregledali smo prve dele učbeniških kompletov: avtorji predvidevajo, da bi jih morali predelati v do 150 urah pouka (NSF: 100 do 150 ur, P: 120 do 150 ur, $\mathrm{C}$ in RP: obseg ni določen, vendar sovpada $z$ NSF in $\mathrm{P})$. V naših razmerah ${ }^{15}$ bi morali prvi del učbenikov obdelati v največ dveh letih. Iz pogovorov z učitelji in opazovanja dela v razredih pa vemo, da se obravnava prvega dela učbenika zavleče vsaj do polovice tretjega letnika. Ko končajo s prvim delom učbenika, se nekateri učitelji sploh ne odločijo za nadaljevanje $\mathrm{z}$ drugim delom, pač pa se zatekajo k fotokopijam.

3 Campus ima uvodne enote posnete na avdio ali na video kaseti.

14 Književna besedila so v obravnavanih učbeniških kompletih različno zastopana. Največ jih vsebuje najstarejši učbenik, Le Nouveau sans frontières, v katerem so avtorji nanja opozarjali celo s posebnim znakom v navodilih.

${ }_{15}$ Tri ure pouka drugega tujega jezika na teden znese 90 ur pouka letno. 


\subsubsection{Mesto bralnega razumevanja v ciljih, kot so si jih zastavili avtorji učbenikov}

Branje in bralno razumevanje v ciljih, ki si jih zastavljajo avtorji učbenikov, ni posebej omenjeno, čeprav po pregledu vseh treh priročnikov za učitelje lahko ugotovimo, da so avtorji starejših dveh, NSF in $\mathrm{P}$, branju vseeno namenjali večjo pozornost.

Avtorji NSF omenjajo, da »ne bodo zanemarili nobene od štirih spretnosti (slušno razumevanje - ustno izražanje - bralno razumevanje - pisno izražanje)《 (NSF, priročnik za učitelja: 3). Aktivnosti, povezane z branjem, so v tem priročniku omenjene v poglavju »Organizacija enot in predlogi za izvedbo«, kjer najdemo navodilo za delo z besedilom, iz katerega je razvidno, naj bi učitelj v razredu dijake uril tudi v boljšem branju:

»Obravnava pisnega dokumenta lahko poteka takole:

- prepoznavanje tipa dokumenta (časopisni članek, sporočilo, pismo, formular, itn.);

- branje in razumevanje naslova (če gre za članek), pisca in naslovnika (če gre za pismo);

- globalno branje besedila, prepoznavanje neznanih besed, formulacija hipotez o smislu besedila na osnovi znanih elementov;

- pozorno branje povedi za povedjo $\mathrm{z}$ razlago neznanih besed.«

(NSF, priročnik za učitelja: 5)

Če lahko presojamo po navodilih $\mathrm{v}$ priročniku za učitelje, sta bralnim aktivnostim največ prostora namenila avtorja Panorame, ki bralno razumevanje umeščata $\mathrm{v}$ pridobivanje splošne komunikacijske kompetence $(\mathrm{P}$, priročnik za učitelja: 3). Poleg tega branju tudi namenjata avtonomen položaj, saj v navodilih za obravnavo uvodnih besedil pravita:

»Učenca soočimo $z$ besedilom, ne da bi mu zastavili drug cilj kot razumevanje besedila. $Z$ različnimi postopki, opisanimi $v$ tem priročniku za učitelje, bomo učenca postopoma pripeljali od globalnega razumevanja do razumevanja podrobnosti.«

(P, priročnik za učitelja: 6)

Avtorja govorita tudi o »bralnem projektu $\aleph^{16}$ : $»$ pri predstavitvi dokumenta gre za projekt, ki presega meje preprostega razumevanja. Gre za iskanje določenih informacij $v$ besedilu, za uporabo besedila $z$ namenom ustnega ali pisnega izražanja, za izdelavo sinteze več dokumentov, itn.« (P, priročnik za učitelja: 7)

Avtorja učbeniškega kompleta Campus v opisu ciljev opozarjata na dejstvo, da je na začetni stopnji učenja (do polovice prve knjige) »poudarek na slušnem razumevanju in ustnem izražanju. To dejstvo ne izključuje uporabe pisnih besedil kot učnih sredstev niti predstavljanja krajših preprostih besedil. Vendar gre predvsem za to, da v razredu ustvarimo komunikacijsko okolje in preprečimo, da bi se slušatelji zatekali v pisna besedila « (C, priročnik za učitelja: 4). Avtorja v ciljih ne predvidevata bralnih aktivnosti. Sklepamo lahko, da je branje drugotnega pomena.

fr. projet de lecture 
Opazimo torej lahko, da se kljub dejstvu, da je pri vseh učbeniških kompletih sodelovala ista avtorica, vloga in položaj branja in bralnih aktivnosti $\mathrm{v}$ učbenikih spreminja: branje je bilo dosti bolj poudarjeno v prvih dveh učbenikih, Panorama pa je bila od vseh treh edini učbenik, ki je gradila tudi na učenju strategij boljšega branja.

$\mathrm{V}$ priročniku za učitelja, ki spremlja Rond point $1, \mathrm{v}$ uvodnem delu bralno razumevanje ni posebej omenjeno; je pa vključeno v ostale aktivnosti - naloge ${ }^{17}$. Avtorji učbeniškega kompleta bralno razumevanje pojmujejo kot sredstvo za dosego drugih ciljev (RP, priročnik za učitelja: 4-7).

\subsubsection{Analiza besedil v učbenikih in delovnih zvezkih}

Pregledali smo 163 besedil v učbenikih in 93 besedil v delovnih zvezkih, skupno torej 256 besedil. Opravili smo analizo avtentičnosti in analizo tipov besedil.

Pri analizi avtentičnosti smo besedila razdelili v naslednje kategorije:

- avtentična besedila $\mathrm{z}$ navedbo vira: označili smo jih z A,

- prirejena besedila z oznako »d'après« (»po«): označili smo jih z Ap,

- na videz avtentična besedila brez navedbe vira: označili smo jih $z$ ?A,

- besedila, pri katerih avtentičnosti ne moremo določiti in so verjetno pisana posebej za učbenik: označili smo jih z ?.

Po posameznih učbeniških kompletih smo prišli do naslednjih rezultatov:

\begin{tabular}{|l|c|c|c|c|c|}
\cline { 2 - 6 } \multicolumn{1}{c|}{} & $\begin{array}{c}\text { vseh } \\
\text { besedil }\end{array}$ & $?$ & ?A & Ap & A \\
\hline NSF & 28 & 24 & 3 & $/$ & 1 \\
\hline NSF/DZ & 38 & 17 & 8 & $/$ & 13 \\
\hline P & 52 & 39 & 6 & 1 & 6 \\
\hline P/DZ & 23 & 16 & 2 & $/$ & 5 \\
\hline C & 48 & 37 & 6 & 1 & 4 \\
\hline C/DZ & 11 & 7 & 3 & $/$ & 1 \\
\hline RP & 35 & 14 & 21 & $/$ & $/$ \\
\hline RP/DZ & 21 & 2 & 19 & $/$ & $/$ \\
\hline
\end{tabular}

Iz tabele lahko razberemo, da v vseh štirih učbeniških kompletih prevladujejo besedila, ki so bila po vsej verjetnosti pisana za učbenike. V učbenikih skoraj ni zaslediti prirejenih besedil, najdemo le po enega v Panorami in Campusu. Avtentičnih besedil je zdaleč največ v najstarejšem učbeniku, Le Nouveau sans frontières 
(v učbeniku in delovnem zvezku skupaj 14), nekoliko manj v Panorami (skupno 11), najmanj pa v najnovejšem učbeniku, Campus-u (skupno 5). V najnovejšem učbeniškem kompletu, Rond point, avtentičnih in prirejenih besedil sploh ni.

Pri besedilih, ki smo jih označili z ?A, torej tistih, ki so navidez avtentična, vendar brez navedbe vira, gre večinoma za sezname oz. liste. Za ta tip besedil Adam meni, da jih komajda lahko še štejemo med opise (Adam, 1997).

Določena takšna besedila se v učbenikih ponavljajo. Tako najdemo koledarje (prvi trije učbeniki), vozne rede (prvi trije učbeniki), sezname prireditev - »Spectacles « (Panorama, Campus), dokumente: osebna izkaznica, potni list, ček (Panorama, Campus), reklame (Panorama, Campus), cenik (Campus), navodilo za cepljenje (Campus), program kinematografov (Campus, RP) in podobno.

Podobne tipe besedil $\mathrm{v}$ določeni meri najdemo tudi med avtentičnimi besedili, se pravi, tistimi, kjer so avtorji učbenikov navedli vir: TV program (Campus), carinski dokument (Campus), različne časopisne naslovnice (Campus, Panorama), časopisne naslove (NSF), reklame (Panorama), statistiko volitev (NSF), kuharski recept (RP). Zastavlja se vprašanje, zakaj so avtorji učbenikov pri nekaterih uradnih dokumentih vir navedli, pri drugih pa ne, saj gre $v$ nekaterih primerih za zelo podobne dokumente (vir je na primer naveden pri formularju carinskega dokumenta, ne pa pri čeku). $Z$ navedbo vira pri besedilih, označenih $z$ ?A, bi se število avtentičnih dokumentov v učbenikih precej povečalo. Po našem mnenju bi učbenik s tem pridobil na verodostojnosti.

\subsubsection{Pregled tipov besedil v povezavi $z$ avtentičnostjo}

Za razvrščanje besedil po tipih smo uporabili Adamovo tipologijo (1997), ki besedile deli na:

- pripovedi,

- opise (z različico »liste « - opisi, ki prinašajo zgolj sezname, na videz brez veznega besedila),

- utemeljevanja,

- razlage,

- dialoge.

Največ avtentičnih besedil pripada opisnemu tipu. Tako v učbenikih najdemo opise:

- besedila iz turističnih vodičev: Guide Paris Combines, La croisière verte, La croisière en bateau, Des cartes pour voyager pas cher (vse P),

- opis predmeta: igrača, ura $(\mathrm{P})$,

- opis vsebine knjig (NSF/DZ),

- članek o maturi (NSF/DZ),

- kuharski recept (RP).

in opise/liste:

- internetne strani (muzeja Louvre, C; založbe CLE, P),

- TV spored (C, P, NSF),

- naslovnice časopisov in revij (C), 
- tabele: La répartition des voix au premier tour des élections (C), Etudes: pourquoi les filles sont meilleures? (NSF/DZ),

- seznam besed: Le palmarès des mots $(\mathrm{P})$,

- časopisni naslovi (NSF/DZ),

- carinski dokument, obrazec za telegram, navodila za telefoniranje (NSF/DZ).

Avtentična besedila, ki spadajo med razlage:

- pisma bralcev $(\mathrm{P} / \mathrm{DZ})$,

- Ils sont étrangers: ils disent pourquoi ils aiment Paris (P),

- sekvenca besedila iz turističnega vodnika: Guide Paris Combines (P/DZ)..

Med avtentičnimi dialoškimi besedili najdemo le dva stripa (NSF in C), en primer je že naveden zgoraj.

Avtentične pripovedi najdemo le v NSF/DZ:

- dva članka iz črne kronike,

- članek o arheološki najdbi iz strokovne revije.

$\mathrm{V}$ pregledanih učbenikih in delovnih zvezkih najdemo le eno utemeljevalno besedilo, oz. le eno utemeljevalno sekvenco, v NSF/DZ.

Opozorili bi radi na dejstvo, da je največ avtentičnih besedil v delovnem zvezku učbenika Le Nouveau sans frontières, se pravi, v najstarejšem učbeniku. Ta učbenik vsebuje tudi avtentična besedila večine zvrsti (manjka le razlaga). Posebej zanimive so pripovedne in utemeljevalna sekvenca, ki jih $\mathrm{v}$ drugih učbenikih ne najdemo.

\section{SKLEP}

Besedila v učbenikih lahko razdelimo na »pedagoška « besedila, se pravi, besedila, ki so tako kot uvodna besedila pisana posebej za učbenik in ostala besedila, ki so bolj ali manj avtentična. Avtorji skoraj ne uporabljajo prirejenih besedil, pač pa uporabljajo veliko besedil, ki so na videz avtentična, vendar njihov vir ni naveden. Med takimi besedili izstopajo opisi, še posebej tisti, ki smo jih poimenovali liste.

Tudi med avtentičnimi besedili je največ opisov in opisov/list. V učbenikih najdemo nekaj pripovedi in razlag, dialogi in utemeljevalna besedila pa so zelo redki. Odsotnost utemeljevalnih besedil ne preseneča; avtorji učbenikov namreč menijo, da so ta besedila pretežka za to stopnjo (Boissinot, 1999). Bolj preseneča odsotnost dialoških besedil, saj v realnih življenjskih situacijah najdemo dosti dialogov, ki so primerni po težavnosti in bi jih lahko uporabili: različni časopisni intervjuji, transkripcije delov filmov in podobno.

Opozoriti velja tudi na dejstvo, da bi avtorji učbenikov t. i. »pedagoška« besedila lahko vsaj v določeni meri nadomestili $\mathrm{z}$ avtentičnimi: primera avtentičnih pripovedi iz NSF, ki ju navajamo, bi lahko nadomestila pripovedne sekvence $\mathrm{v}$ 
lekcijah istega učbenika. Seveda bi bilo v tem primeru treba zgodbo uvodnih besedil, ki se odvija skozi več enot učbenika, prilagoditi izbranemu avtentičnemu besedilu.

Nobena od obeh v uvodu zastavljenih predpostavk ni potrjena v celoti. Avtentična besedila res najdemo $v$ večini analiziranih učbeniških kompletov (v vseh, razen $v$ najnovejšem), je pa očitno, da se njihovo število zmanjšuje od najstarejšega do najnovejšega učbenika. Dejstvo je paradoksalno, saj so danes avtentični dokumenti vseh vrst dosegljivi na veliko lažje načine kot $\mathrm{v}$ času nastanka Le nouveau sans frontières, najstarejšega analiziranega učbenika. Kje so vzroki za to, ne vemo, lahko pa predpostavljamo, da je manjša raba avtentičnih gradiv $\mathrm{v}$ učbenikih povezana $\mathrm{z}$ avtorskimi pravicami (ki se danes upoštevajo veliko bolj kot pred dvajsetimi leti) in posledično denarjem, ki ga za to namenijo založbe. Kljub dostopnosti avtentičnih gradiv je iskanje in izdelava $\mathrm{z}$ njimi povezanih nalog za učitelja veliko breme, zato bi si bilo v bodoče želeti več takih gradiv tudi v učbenikih.

\section{BIBLIOGRAFIJA}

ADAM, J.-M. (1997) Les textes: types et prototypes. Paris: Nathan Université.

BEACCO, J.-C., DAROT, M. (1984) Analyses de discours: lecture et expression. Paris: Hachette/Larousse.

BOISSINOT, A. (1999) Les textes argumentatifs. Toulouse: Bertrand Lacoste CRDP Midi-Pyrénées.

BOYER, H., BUTZBACH-RIVERA, M., PENDANX, M. (1990) Nouvelle introduction à la didactique du français langue étrangère. Paris: CLE International.

CUQ, J.-P., GRUCA, I. (2002) Cours de didactique du français langue étrangère et seconde. Grenoble: Presses Universitaires de Grenoble.

CUQ, J.-P. (ed.) (2003) Dictionnaire de didactique du français langue étrangère et seconde, Paris: Clé International.

DEBYSER, F. (1979) La découverte du parlé grâce au document sonore. Le français dans le monde 145, 80-81.

DE FERRARI, M. (2006) Le traitement des documents authentiques. http://www.francparler.org/articles/deferrari2006.htm, prebrano 21. 9. 2010

DEMARI, J.-C. (2004) «Authentique», mode d'emploi. Le français dans le monde 331, 32-33.

GRELLET, F. (1981) Developing Reading Skills. Cambridge: Cambridge University Press.

HUGHES, A. (1989) Testing for Language Teachers. Cambridge: Cambridge University Press.

JUSTIN, J. (2003) Učbenik kot dejavnik uspešnosti kurikularne prenove. Ljubljana: ISH

KAWECKI, R. (2004) De l'utilité des documents authentiques. Le français dans le monde, 31-32. 
LEMEUNIER-QUERE, M. (2004) Créer du matériel didactique. Le français dans le monde 331, 29-30.

LEWKOWICZ, J. A. (1997) Authentic for whom? Does authenticity really matter?

Huhta, A. et al: Current Developments and Alternatives in Language Assessment - Proceedings of LTRC 96. Jyväskyla: University of Jyväskyla, 164-184.

MORLAT, J.-M. (2009) La problématique du document authentique de langue B du Baccalauréat International. http://www.edufle.net/La-problematique-du-document, prebrano 10. 9. 2010

PORTINE, H. (1981) Un récit dans l'argumentation. Langue française 50, 75-90.

URQUHART, S., WEIR, C. (1998) Reading in a second language: process, product and practice. London, New York: Longman.

VIGNER, G. (1980) Didactique fonctionnelle du français. Pariz: Hachette.

VIGNER, G. (1997) La représentation du savoir: mise en page et mise en texte dans les manuels scolaires. Ecritures et textes d'aujourd'hui, Cahiers du français contemporain, 48-82.

\section{Učbeniki}

DOMINIQUE, P./J. GIRARDET, J./M. VERDELHAN (1998) Le nowveau sans frontières 1. Paris: CLE International.

VERDELHAN M., P. DOMINIQUE/J. GIRARDET (1988) Le nouveau sans frontières 1 , cahier d'exercices. Paris: CLE International.

GIRARDET, J. (1988) Le nouveau sans frontières 1, Le livre du professeur. Paris: CLE International.

GIRARDET, J./J.-M. CRIDLIG (2000) Panorama. Paris: CLE International.

GIRARDET, J./J.-M. CRIDLIG (1996) Panorama 1 - cahier d'exercices. Paris: CLE International.

GIRARDET, J./J.-M. CRIDLIG (1996) Panorama 1 - livre du professeur. Paris: CLE International.

GIRARDET, J./J. PECHEUR (2002) Campus. Paris: CLE International.

GIRARDET, J./J. PECHEUR (2002) Campus. Cahier d'exercices. Paris: CLE International.

GIRARDET, J./J. PECHEUR (2002) Campus. Livre du professeur. Paris: CLE International.

LABASCOULE, J./C. LAUSE/C. ROYER (2004) Rond point. Barcelona: Difusión/ PUG.

LABASCOULE, J./Ph. LIRIA/M. R. RODRIGUEZ/C. ROYER (2004) Rond point cabier d'exercices. Barcelona: Difusión/PUG.

DENYER, M. (2005) Rond point-guide pédagogique. Barcelona: Difusión/PUG. 


\section{POVZETEK}

\section{Avtentična besedila pri pouku francoščine kot tujega jezika}

Namen pričujočega članka je razmislek o rabi avtentičnih besedil pri pouku francoščine kot tujega jezika. Avtorica izhaja iz analize besedil v štirih učbeniških kompletih (Le nouveau sans frontières, Panorama, Campus in Rond point), ki so se ali se še uporabljajo pri pouku francoščine kot tujega jezika. Najprej poda definicije avtentičnosti in pregled uporabe avtentičnih gradiv skozi zgodovino. Pri pregledu besedil v korpusu besedila razdeli na avtentična, prirejena, navidezno avtentična in besedila, pri katerih o avtentičnosti ni mogoče sklepati. Analizo avtentičnosti opravi tudi v povezavi z analizo tipov besedil (po Adamu). Izhaja iz dveh predpostavk; predvideva, da bodo avtentična besedila prisotna $\mathrm{v}$ vseh analiziranih učbenikih in da bo, glede na dostopnost gradiv, njihovo število večje $\mathrm{v}$ novejših učbenikih. Nobena od obeh hipotez ni potrjena; avtentična besedila so prisotna $\mathrm{V}$ prvih treh kompletih, ne pa tudi v najnovejšem; njihovo število pa je največje prav v najstarejšem učbeniškem kompletu, Le nouveau sans frontières. Glede na dostopnost avtentičnih predlog vseh vrst je rezultat analize presenetljiv. Po avtoričinem mnenju bi v učbenike veljalo vključiti več avtentičnih besedil in z njimi bolj osmisliti pouk tujega jezika.

Ključne besede: Pouk tujega jezika, avtentična besedila, učbeniki francoščine kot tujega jezika, tipi besedil

\section{ABSTRACT}

\section{Authentic texts in teaching French as a foreign language}

The present paper is aimed at providing a reflection on the use of authentic texts in French as a foreign language classroom. The author bases herself on an analysis of texts taken from four textbook sets (Le nouveau sans frontières, Panorama, Campus and Rond point), which were or are still used in teaching French as a foreign language. Initially, a definition of authenticity and a survey of authentic material usage through history are provided. In the overview of the texts forming the corpus the texts are divided into authentic, adapted, apparently authentic and those for which no assumption can be made as to their authenticity. The authenticity analysis is also carried out by taking into account the analysis of/categorisation into text types (according to Adam). The author proceeds from two premises, i.e. firstly she foresees that authentic texts will be present in all textbooks analysed and secondly, considering the greater accessibility of materials, that their presence will be more pronounced in recent textbooks. However, none of the two hypotheses is confirmed, as authentic texts are found in the first three textbook sets, but not in the most recent one, while their presence is most pronounced in the oldest textbook set, i.e. in Le nouveau sans frontières. The result of the analysis is thus somehow surprising given the overall accessibility of all kinds of authentic materials. In the author's opinion more authentic texts should be included into textbooks to thus enhance the purposefulness of the foreign language classroom.

Keywords: Foreign language classroom, authentic text, textbook for French as a foreign language, text types. 